\title{
ROLE OF ENDOVASCULAR INTERVENTION IN ILIAC ARTERY DISEASE TASC C AND D CLASSIFICATION
}

\author{
By
Tamer El-Sayed Abo Gazia, Sameh El-Sayed El-Imam, Bosat Elwany Bosat and Yehia Kamal Sadek \\ Department of Vascular Surgery, Faculty of Medicine for (Girls), Al-Azhar University, \\ Cairo, Egypt
}

Correspondence to: Tamer Elsayed Abogazia,

Mobile: 01091961767, E-mail: dr.tamer.gazia@gmail.com

\begin{abstract}
Background: For more than forty years, endarterectomy and bypass grafting have been the primary means of surgically revascularizing peripheral vessels threatened by atherosclerotic diseases. However, with today's endovascular technology, stenosis and occlusions in nearly every circulatory system can he approached intraluminally with balloon dilation and intravascular stents.

Objective: To evaluate the technical success rates, primary patency, limb salvage, patient survival and complications for TASC C, and D iliac lesions treated by endovascular procedure. Additionally, the influence of the access site and the clinical outcomes were analyzed.

Patients and Method: Between 2017 and 2019, data from 40 consecutive patients at Al-Zahra'a University Hospital and Damanhor Teaching Hospital with 47 chronic iliac artery stenosis, and/or occlusion who were treated with EVT were reviewed.

Results: The procedure time was longer for TASC D lesions than for TASC C lesions $(180.43 \pm 45.97$ VS131.69 $\pm 37.49: p=0.001$ ). There were two postoperative deaths in the TASC D lesion group, with the cause being one myocardial infarction, and one postoperative hospital acquired pneumonia. The total perioperative complication occurred in the TASC D lesions was [four (10\%) vs. zero; $\mathrm{p}=0.011$ ] TASC C lesions. Corresponding 2-year primary patency rates were $100 \%$ in TASC C lesions, $71.4 \%$ in TASC D lesions, and for all cases were $87.5 \%$.

Conclusion: The outcomes of EVT for TASC C and D aorto-iliac lesions were acceptable, with better technical success in TASC C lesions than in TASC D lesions. The 2-year patency rate for both TASC C and TASC D lesions was acceptable, and brachial access was useful for complex anatomy.
\end{abstract}

Keywords: Endovascular procedures, iliac artery, Trans-Atlantic Inter- Society Consensus (TASC), Patency, Peripheral artery disease.

\section{INTRODUCTION}

The long-term durability of open bypass is better than that of endovascular treatment (EVT) for Trans-Atlantic InterSociety Consensus (TASC) C and D aorto-iliac lesions (Norgren et al., 2017). However, an operative mortality rate of
$2.9 \%$ and a complication rate of $15.3 \%$ make open surgery a less attractive option (Ahn et al., 2017).

Major changes were made between the TASC I and TASC II classification, Satisfactory results were reported with EVT for TASC C and D aorto-iliac 
lesions, and attempted to treat TASC C and TASC D lesions with EVT (Gandini et al., 2018). Moreover, technical and device improvements have encouraged vascular surgeons to perform EVT for TASC C or TASC D aorto-iliac lesions during the last 10 years (Ahn et al., 2017).

Primary stent placement for complex iliac artery occlusive disease provides acceptable long-term outcomes, but takes relatively longer and shows a higher incidence of complications compared with simple disease. Endovascular treatment for iliac artery occlusive disease is considered as an alternative to open surgery even for TASC-II C/D disease (Ye et al., 2011).

The present work aimed to evaluate the technical success rates, primary patency, Limb salvage, patient survival and complications for TASC C and D iliac lesions.

\section{PATIENTS AND METHODS}

Between 2017 and 2019, data from 40 consecutive patients at Al-Zahra'a University Hospital, and Damanhor Teaching Hospital with 47 chronic iliac artery stenosis and/or occlusion who were treated with EVT were retrospectively reviewed.

The TASC II classification of the disease severity for aorto-iliac lesions was used to define the lesion category. The number of patients with TASC C and D lesion morphology was 26 (28 limbs), and 14 (19 limbs) respectively. Endovascular first approach in all patients was the treatment of choice during our study period.
All patients were judged to be candidates for EVT if they reported disabling claudication, failed medical therapy, or rest pain or gangrene [Rutherford category (3, 4, 5 and 6) or Fontaine stage (IIb-IV)].

Electronic medical records and angiography images were reviewed for demographic data, anatomic lesion, procedural factors, complications, and other outcome variables. Patients with acute limb ischemia, restenotic lesions, diagnostic arteriography, or no intention to treat were excluded.

All patients underwent preoperative ankle-brachial indices (ABI), and duplex ultrasonography examinations to determine the need for EVT. Additionally, all patients had at least one radiological imaging including computed tomography angiography (CTA) or magnetic resonance angiography, before therapeutic angiography. The procedure was performed in a fully equipped endovascular suite. The procedure was performed under local infiltration anesthesia. The brachial approach was reserved for patients with difficulty in crossing proximal or ostial occlusion by a contralateral approach or in bilateral iliac lesions.

The length and diameter of the lesion was judged by intraoperative arteriograms. Routine stenting was performed in all patients. Predilatation of the occlusion before stent deployment was performed. Self-expandable stents for long-segment occlusions or balloonexpandable stents for short-segment occlusions (mostly at the common iliac artery orifice) were preferred. 
All patients were given $325 \mathrm{mg}$ of aspirin and $300 \mathrm{mg}$ of clopidogrel immediately postoperatively, $75 \mathrm{mg}$ of clopidogrel for 6 weeks postoperatively, and $100 \mathrm{mg}$ of aspirin indefinitely (lifelong enteric coated acetyl salicylic acid [ECASA]).

Technical success was defined as $>30$ $\%$ residual stenosis on angiography. Procedure-related morbidity and mortality rates within 30 days were determined.

Regular visits were attempted after 1month, 6 months, I year and 2 years. Restenosis was defined as $>50 \%$ decrease in luminal diameter seen on non- invasive imaging or angiography.

The treated aorto-iliac lesions were assessed by duplex ultrasonography examination, and ABI was measured at 1 month and 6 months during the first postoperative year and annually thereafter. CTA was performed when there were recurrent symptoms, a decrease of $\geq 0.15$ in $\mathrm{ABI}$, and/or an increase of $>300 \mathrm{~cm} / \mathrm{s}$ in the peak systolic velocity.

\section{Statistical analysis:}

Data were fed to the computer and analyzed using IBM SPSS software package version 20.0. (Armonk, NY: IBM Corp) Qualitative data were described using number and percent. The Kolmogorov-Smirnov test was used to verify the normality of distribution Quantitative data were described using range (minimum and maximum), mean, standard deviation and median. Significance of the obtained results was judged at the 5\% level. Comparisons between patients with TASC $\mathrm{C}$ lesions and TASC D lesions were performed using the Student's t test. Primary patency of the percutaneous transluminal angioplasty site was analyzed using the Kaplan-Meier analysis with log-rank test applied.

\section{RESULTS}

The number of patients with TASC $\mathrm{C}$ and $\mathrm{D}$ lesion morphology was: 26 $(65 \%)$ and 14 (35\%), respectively. Demographic data were as following; Min. - Max WAS 50.0 - 75.0 which meant that aorto-iliac atherosclerosis is was disease of elderly. Sex distribution showed a male preference of this disease. According to co-morbidities there were high incidences of DM, followed by HTN then IHD. Smoking prevalence was $62.5 \%$. Showed high correlation between atherosclerosis of iliac arteries and both DM and smoking (Table 1). 
Table (1): Demographic data and co-morbidities distribution of the study group

\begin{tabular}{|c|c|c|c|c|}
\hline \multirow{2}{*}{ Parameters } & \multirow{2}{*}{$\begin{array}{c}\text { Total } \\
(n=40)\end{array}$} & \multicolumn{2}{|c|}{ TASC type } & \multirow[b]{2}{*}{$\mathbf{p}$} \\
\hline & & $\begin{array}{l}\text { TASC C } \\
(n=26)\end{array}$ & $\begin{array}{c}\text { TASC D } \\
(n=14)\end{array}$ & \\
\hline \multicolumn{5}{|l|}{ Sex } \\
\hline Male & $30(75 \%)$ & $19(73.1)$ & $11(78.6 \%)$ & \multirow{2}{*}{1.000} \\
\hline Female & $10(25 \%)$ & $7(26.9 \%)$ & $3(21.4 \%)$ & \\
\hline \multicolumn{5}{|l|}{ Age (years) } \\
\hline Min. - Max. & $50-75$ & $50-70$ & $51-75$ & \multirow{3}{*}{0.001} \\
\hline Mean \pm SD. & $65.5 \pm 7.4$ & $59.8 \pm 6.3$ & $67.6 \pm 6.6$ & \\
\hline Median (IQR) & $63(56.3-69)$ & $59(55-66)$ & $68.5(66.5-72.3)$ & \\
\hline \multicolumn{5}{|l|}{ Risk factors } \\
\hline $\mathrm{DM}$ & $31(77.5 \%)$ & $21(80.8 \%)$ & $10(71.4 \%)$ & 0.694 \\
\hline Smoking & $25(62.5 \%)$ & $15(57.7 \%)$ & $10(71.4 \%)$ & 0.392 \\
\hline HTN & $21(52.5 \%)$ & $9(34.6 \%)$ & $12(85.7 \%)$ & 0.002 \\
\hline IHD & $18(45 \%)$ & $8(30.8 \%)$ & $10(71.4 \%)$ & 0.014 \\
\hline Dyslipidemia & $16(40 \%)$ & $8(30.8 \%)$ & $8(57.1 \%)$ & 0.104 \\
\hline CVD & $6(15 \%)$ & $0(0 \%)$ & $6(42.9 \%)$ & 0.001 \\
\hline Renal CR>1.2 & $5(12.5 \%)$ & $1(3.8 \%)$ & $4(28.6 \%)$ & 0.043 \\
\hline COPD & $4(10 \%)$ & $1(3.8 \%)$ & $3(21.4 \%)$ & 0.115 \\
\hline
\end{tabular}

$\mathrm{p}$ : $\mathrm{p}$ value for comparing between the two studied groups

A total of 47 limbs (40 patients) had been evaluated with anatomic variables, access site, and time of procedure. Most of the patients were treated for claudication $(55 \%)$. Occlusion was higher in TASC D lesions than in TASC C lesions. Bilateral iliac artery occlusions were observed in seven patients, five of which were in TASC D lesions. The procedure time was longer for TASC D lesions than for TASC C lesions (180.43 \pm 45.97 VS131.69 \pm 37.49). Varieties of stents were used in $100 \%$ of TASC C lesions and in $85.7 \%$ of TASC D lesions (Table 2).

Table (2): Clinical presentation, completion angiography and procedure time distribution of the studied cases

\begin{tabular}{|c|c|c|c|c|}
\hline \multirow{2}{*}{ Parameters } & \multirow{2}{*}{$\begin{array}{c}\text { Total } \\
(n=40)\end{array}$} & \multicolumn{2}{|c|}{ TASC type } & \multirow[b]{2}{*}{$\mathbf{P}$} \\
\hline & & $\begin{array}{l}\text { TASC C } \\
(n=26)\end{array}$ & $\begin{array}{l}\text { TASC D } \\
(n=14)\end{array}$ & \\
\hline Disable claudication & $22(55 \%)$ & $11(42.3 \%)$ & $11(78.6 \%)$ & 0.028 \\
\hline Rest Pain & $13(32.5 \%)$ & $7(26.9 \%)$ & $6(42.9 \%)$ & 0.480 \\
\hline Gangrene & $21(52.5 \%)$ & $13(50 \%)$ & $8(57.1 \%)$ & 0.666 \\
\hline \multicolumn{5}{|c|}{ Completion angiography } \\
\hline Passed & $38(95 \%)$ & $26(100 \%)$ & $12(85.7 \%)$ & \multirow{2}{*}{0.117} \\
\hline Failed & $2(5 \%)$ & $0(0 \%)$ & $2(14.3 \%)$ & \\
\hline \multicolumn{5}{|l|}{ Procedure time/min } \\
\hline Min. - Max. & $70-245$ & $70-213$ & $91-245$ & \multirow{3}{*}{0.001} \\
\hline Mean \pm SD. & $148.75 \pm 46.5$ & $131.7 \pm 37.5$ & $180.4 \pm 46$ & \\
\hline Median (IQR) & $\begin{array}{c}137(121.3- \\
180.8)\end{array}$ & $\begin{array}{c}128(108.5- \\
143.3)\end{array}$ & $\begin{array}{c}178.5(137- \\
217.8) \\
\end{array}$ & \\
\hline
\end{tabular}

$\mathrm{p}: \mathrm{p}$ value for comparing between the two studied groups 
There were two postoperative deaths in the TASC D lesion group, with the cause being one myocardial infarction and one postoperative hospital acquired pneumonia. The total postoperative complication occurred in the TASC D lesion group four cases. These complications included one myocardial infarction, one hospital acquired pneumonia, one postoperative nephropathy, and one sheath site hematoma that resolved in two weeks without any surgical interference (Table3).

Table (3): Post-operative complications distribution of the studied cases

\begin{tabular}{|l|c|c|c|c|}
\hline \multirow{2}{*}{$\begin{array}{l}\text { Post-operative } \\
\text { complications }\end{array}$} & \multirow{2}{*}{$\begin{array}{c}\text { Total } \\
(\mathbf{n = 4 0 )}\end{array}$} & \begin{tabular}{c} 
TASC C \\
\cline { 3 - 4 }
\end{tabular} & $\begin{array}{c}\text { TASC D } \\
(\mathbf{n = 2 6})\end{array}$ & \multirow{2}{*}{$\mathbf{p}$} \\
\hline No & $36(90 \%)$ & $26(100 \%)$ & $10(71.4 \%)$ & \\
\hline Myocardial infarction & $1(2.5 \%)$ & $0(0 \%)$ & $1(7.1 \%)$ & \multirow{2}{*}{0.011} \\
\hline Post -operative pneumonia & $1(2.5 \%)$ & $0(0 \%)$ & $1(7.1 \%)$ & \\
\cline { 1 - 4 } Post-operative nephropathy & $1(2.5 \%)$ & $0(0 \%)$ & $1(7.1 \%)$ & \\
\hline Sheath site hematoma & $1(2.5 \%)$ & $0(0 \%)$ & $1(7.1 \%)$ & \\
\hline
\end{tabular}

MC: Monte Carlo

$\mathrm{p}$ : $\mathrm{p}$ value for comparing between the two studied groups

The corresponding 2-year primary patency rates were $100 \%$ for TASC C lesions and $71.4 \%$ for TASC D lesions. Primary patency rate for all cases were
87.5\% (Figure 1). However, there was no statistically significant difference between the groups considering the primary patency.

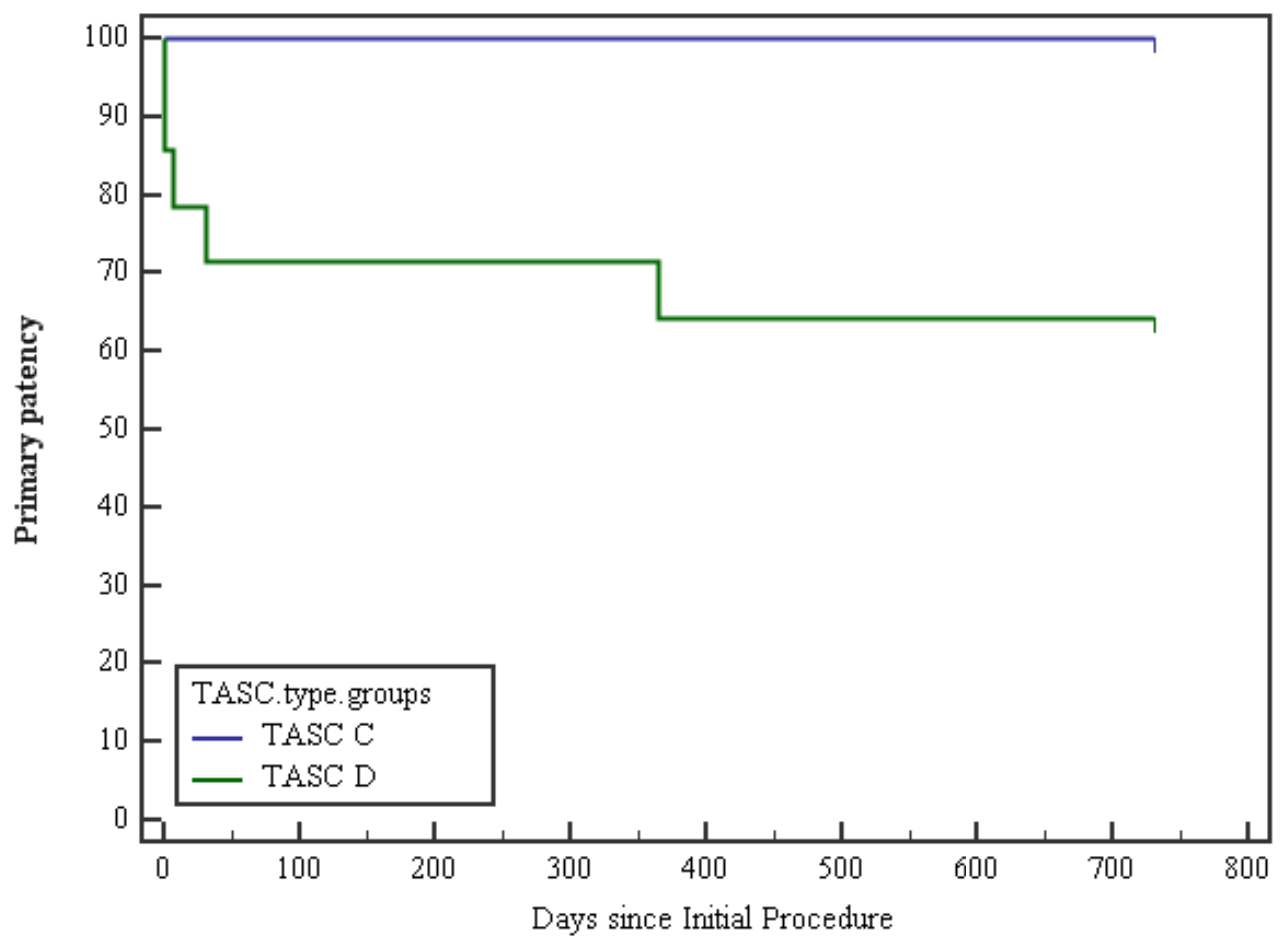

Figure (1): Kaplan-Meier curve for Primary patency rate 


\section{DISCUSSION}

This study demonstrated a $100 \%$ technical success rate and a $100 \%$ primary patency at 2 years for TASC $\mathrm{C}$ lesions, and $85.7 \%$ technical success rate and $71.4 \%$ primary patency at 2 years for TASC D lesions. The complication rate was $0 \%$ for TASC C and $10 \%$ for TASC $\mathrm{D}$ lesions.

Considering the $95 \%$ technical success rate in this study, the results were high compared with those of TASC A and TASC B lesions treated by EVT that were 98\% by Galaria and Davies (2015). Additionally, easy-to-repeat procedures for re-stenosis constitute one reason for the increasing trend for EVT (Galaria and Davis, 2015).

Both intraluminal endovascular interventions and subintimal angioplasty can be applied to treat iliac chronic total occlusion lesions. There was no difference in the primary patency $(74 \%$ for the intraluminal approach and $76 \%$ for subintimal angioplasty at the 3-year follow up) (Chen et al, 2011).

We preferred primary stenting in TASC C and D aorto-iliac lesions. AbuRahma et al. reported an overall early clinical success rate of $93 \%$ for primary stenting and $46 \%$ for selective stenting in TASC C and TASC D iliac lesions (AbuRahma, 2007). A 2- year primary patency rate of $100 \%$ in TASC C lesions and $71.4 \%$ in TASC D lesions in this study was comparable with previous reports.

Ahn et al. (2017) reported that puncture sites were $26.6 \%$ Bifemoral, $20 \%$ brachial, $33.3 \%$ contralateral, $13.3 \%$ Ipsilateral, and $6.6 \%$ both brachial and femoral. In our study, our results were not far away from Ahn et al results, access of puncture sites were $15 \%$ Bifemoral, $22.5 \%$ brachial, $35 \%$ contralateral, $15 \%$ Ipsilateral, and $12.5 \%$ both brachial and femoral. Brachial and femoral access were found in 5 cases of TASC D and 0 in TASC C, This means that tight iliac lesions may need 1 st double access to be easily managed.

Brachial access is widely used in coronary interventions, but much less so in noncoronary interventions. The main reasons for reluctant use of brachial access are complications, such as hematoma and arterial thromboembolism. These complications were reported in $6 \%$ to $8 \%$ of cases (Alvarez-Tostado et al., 2019).

In our study, only left brachial artery accesses were performed in seven limbs $(26.9 \%)$ in TASC C lesions and in two limbs $(14.3 \%)$ in TASC D lesions. We performed brachial access using the Seldinger technique in all patients, and performed surgical closure after making a small incision. There were no complications related to the use of brachial access. The brachial approach offered a better pushability in complex endovascular procedures, while the surgical cut-down method can also be used safely (Alvarez-Tostado et al., 2019).

The technical success rate was higher in TASC $\mathrm{C}$ lesions than in TASC D lesions, and complications were fewer in TASC $\mathrm{C}$ lesions than in TASC D lesions. In a meta-analysis, comparing TASC C lesions and TASC D lesions, no significant difference was found between the two groups when considering technical success (Ye et al., 2011). Other factors may have played a role in the 
patients as important as the length of the occlusion. Due to potential differences in patient selection, a direct comparison of these results is not possible (Ozkan et al., 2010).

When comparing EVT with open surgery, mortality and morbidity should also be considered. In this meta-analysis, the operative mortality of EVT for TASC $\mathrm{C}$ and TASC D aorto-iliac lesions was $2.9 \%$ (95\% CI, $2.4 \%-3.4 \%$ ), and the complication rate was $15.3 \%(95 \% \mathrm{CI}$, $11.5 \%-20 \%$ ). A prior meta-analysis of 25 articles showed a postoperative mortality rate of $4.4 \%$ and a complication rate of $12.2 \%$ for $\mathrm{ABF}$ (de Varies and Hunink, 2017). Due to potential differences in patient selection when deciding on open or endovascular treatment and variations in type and severity of complications, a direct comparison of these results is not possible (Ye et al., 2011).

Five-year primary patency ranged from $60 \%$ to $86 \%$, with secondary patency rates of $80 \%$ to $98 \%$. In patients with chronic iliac occlusions, successful recanalization was accomplished in nearly $90 \%$ of patients, with marked clinical improvement in the vast majority (Powell and Rzucidlo, 2018). In another series of iliac artery CTOs, primary patency at 5 years in the CTO group was $82 \%$ versus $91 \%$ in patients treated for stenosis (Pulli et al., 2011).

Endovascular treatment for iliac artery occlusive disease can be considered an alternative to open surgery for TASC-II C and $\mathrm{D}$ iliac lesions, especially in surgically unfit patients or those who refuse surgical intervention and kissing stenting is a safe procedure. Although endovascular treatment is amenable to all patients, it is particularly beneficial for older patients with limited life expectancy and associated multiple comorbidities such as diabetes, hypertension and cardiac compromise owing to the less invasive nature of the endovascular procedure and its high patency rate compared with surgery.

Some analyzed data were retrospective, although it was a prospective data collection that originated from only two institutions. The techniques, equipment, and my experience also changed during data collecting. This may have resulted in an overestimation of the technical success rate.

Our study had some limitations. The estimated time was just was2 years, the number of patents was just forty, and the number of TASC C $(65 \%)$ lesions is double the number of TASC D (35\%) lesions, the technical success rate may have been overestimated.

We recommended also assessing the grade of calcifications at the level of the treated iliac lesion (Calcification score), axial CTA images may be used. Circumferential grade was measured by assessing the presence of calcium in one or more of the four 90 sectors: score 1 (0$90)$, score 2 (0-180), score 3 (0-270), and score $4(0-360)$.

\section{CONCLUSION}

Endovascular treatment for iliac artery occlusive disease can be considered an alternative to open surgery for TASC-II C and D iliac lesions, especially in surgically unfit patients or those who refuse surgical intervention and kissing stenting is a safe procedure. Although endovascular treatment is amenable to all 
patients, it is particularly beneficial for older patients with limited life expectancy and associated multiple comorbidities such as diabetes, hypertension and cardiac compromise owing to the less invasive nature of the endovascular procedure and its high patency rate compared with surgery.

\section{REFERENCES}

1. AbuRahma AF, Hayes JD, Flaherty SK, and Peery W (2017): Primary iliac stenting versus transluminal angioplasty with selective stenting. J Vasc Surg., 46(5):965970 .

2. Ahn S, Park K M, Kim Y K, Kim J I, Moon I S, Hong K C, and Kim J Y (2017): Outcomes of endovascular treatment for TASC C and D aorto-iliac lesions. Asian journal of surgery, 40(3), 215-220.

3. Alvarez-Tostado JA, Moise MA, Bena JF, Pavkov M L, Greenberg R K, Clair D G, and Kashyap V S (2019): The brachial artery: a critical access for endovascular procedures. J Vasc Surg., 49:378-385.

4. Chen BL, Holt HR, Day JD Stout C L, Stokes G K, and Panneton J M (2011): Subintimal angioplasty of chronic total occlusion in iliac arteries: a safe and durable option. J Vasc Surg., 53: 367-373.

5. De Vries $S O$ and Hunink $M G$ (2017): Results of aortic bifurcation grafts for aortoiliac occlusive disease: a meta-analysis. Journal of Vascular Surgery, 26(4): 558-569.

6. Galaria II and Davies MG (2015): Percutaneous transluminal revascularization for iliac occlusive disease: long-term outcomes in Trans- Atlantic Inter-Society
Consensus A and B lesions. Ann Vasc Surg., 19:352-360.

7. Gandini R, Fabiano S, Chiocchi M, Chiappa R, and Simonetti G (2018): Percutaneous treatment in iliac artery occlusion: long-term results. Cardiovasc Intervent Radiol. , 31:1069-1076.

8. Norgren L, Hiatt WR, Dormandy JA, Nehler M R, Harris K A, and Fowkes F G (2017): TASC II Working Group: InterSociety Consensus for the Management of Peripheral Arterial Disease (TASC II). J Vasc Surg; 45(supplS)., S5-S67.

9. Ozkan U, Oguzkurt L, and Tercan F (2010): Technique, complication, and longterm outcome for endovascular treatment of iliac artery occlusion. Cardiovasc Intervent Radiol., 33:18-24.

10. Powell R J and Rzucidlo EM (2018): Aortoiliac Disease: Endovascular Treatment. Rutherford's Vascular Surgery E-Book., 9th Edition, 108:1424-1336.

11. Pulli R, Dorigo W, Fargion A, Innocenti A, Pratesi G, Marek J, and Pratesi C (2011): Early and long-term comparison of endovascular treatment of iliac artery occlusions and stenosis. J Vasc Surg., 53:9298.

12. Ye W, Liu CW, Ricco J B, Mani $K$, Zeng R, and Jiang J (2011): Early and late outcomes of percutaneous treatment of Transatlantic Inter-Society Consensus class C and D aorto-iliac lesions. J Vasc Surg., 53(6): 1728-1737. 


\section{دور التدخل الوعائي للثريان الحرقفي لمرضى قصور الاورة

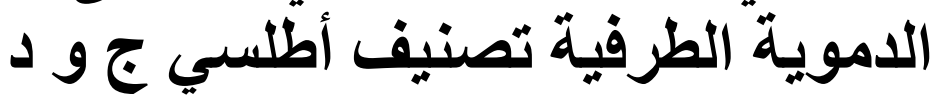

تامر السيد أبوجازية، سامح السيد الامام، بساط علواني بساط، يحي كمال صادق قسم جراحة الأوعية الاموية، كلية طب بنات، جامعة الأزهر، القاهرة

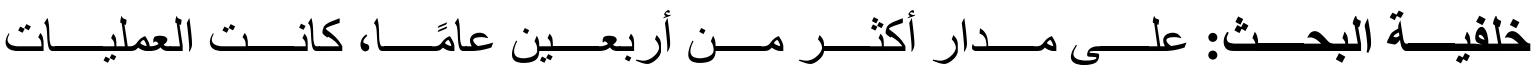

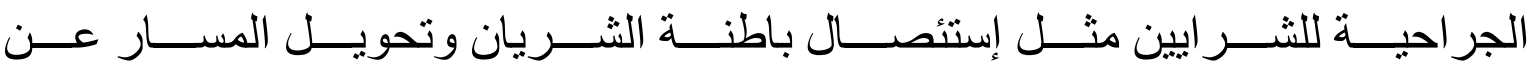

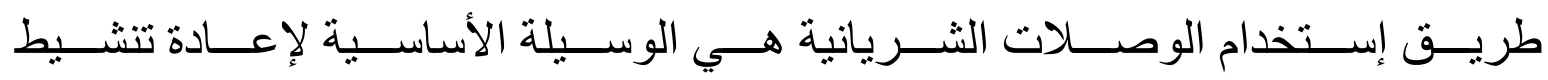

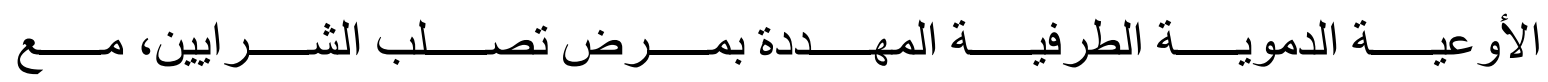

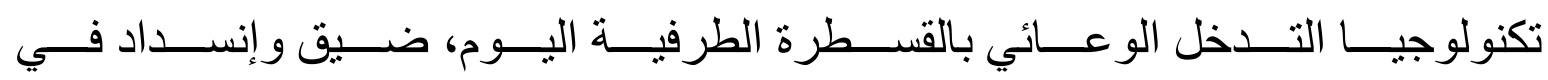

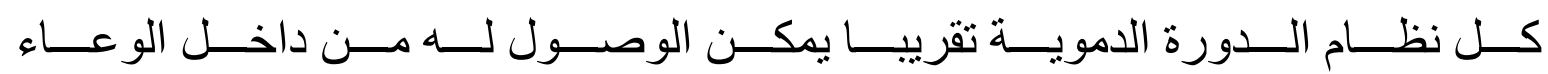
الدموي وتوسيعه عن طريق البالونات ووضع دعامة شريانيا.

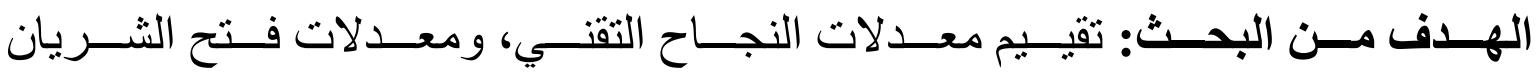

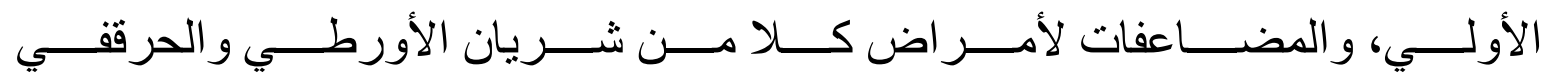

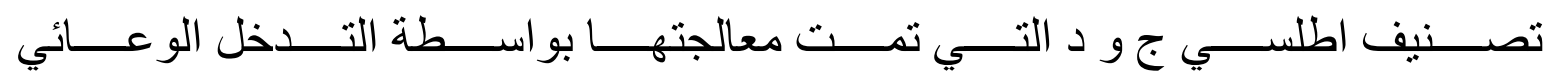
للقسطرة الطرفية.

المرضــــي وطــــق البحــــ: مــن 2017 الـــى 2019 تــــ تجميـــع بيانـــات 40

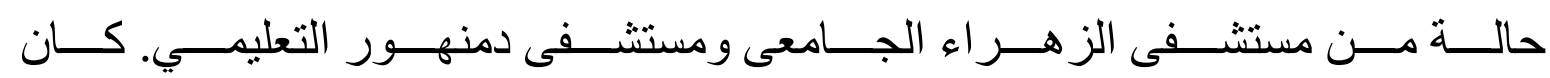

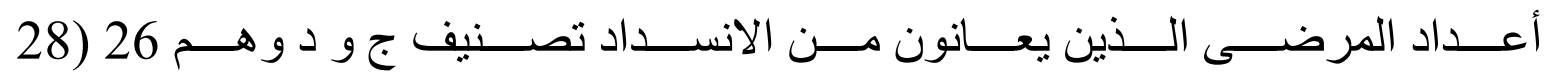

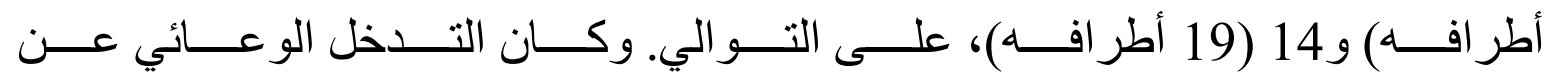

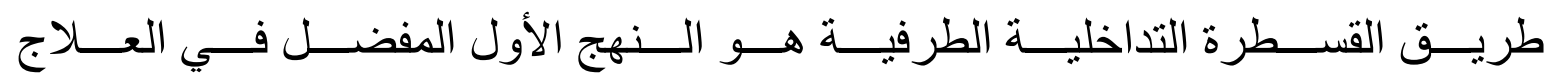
مع وضع إجباري للاعامات الأولية.

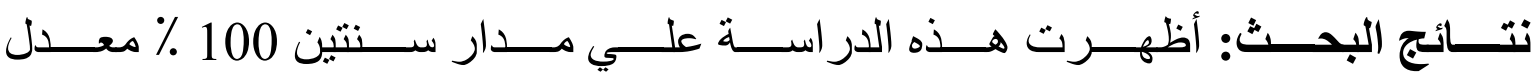

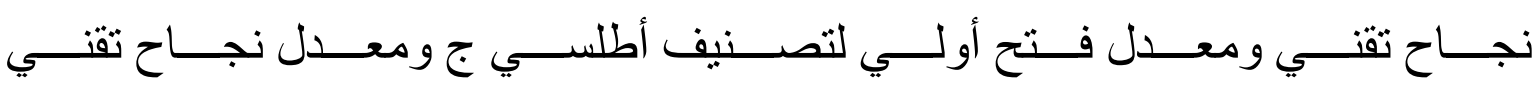




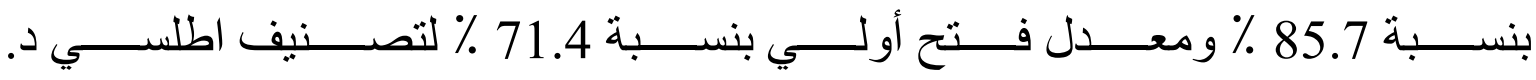

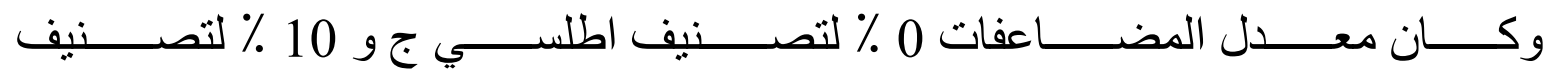
اطلسي د.

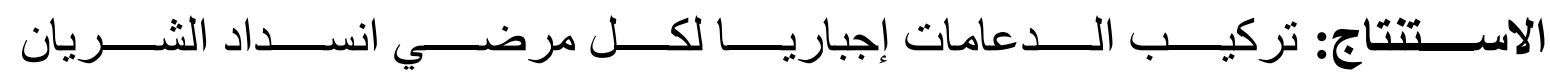

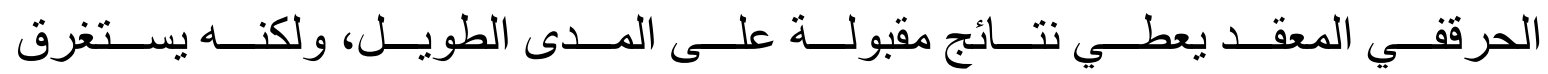

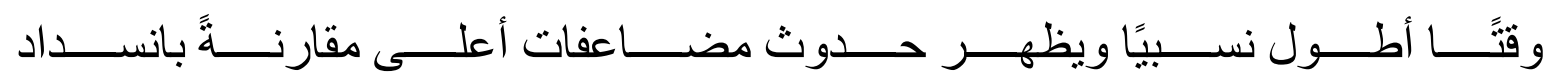

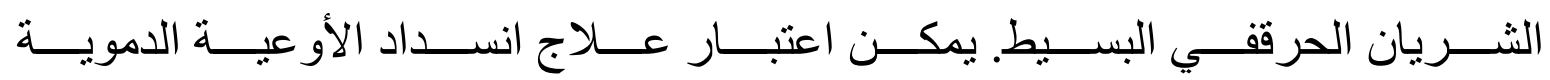

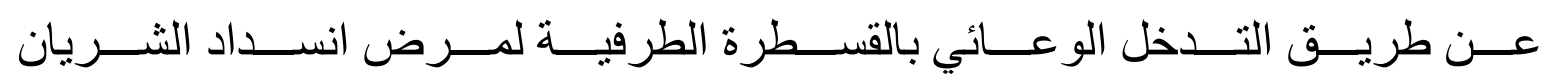

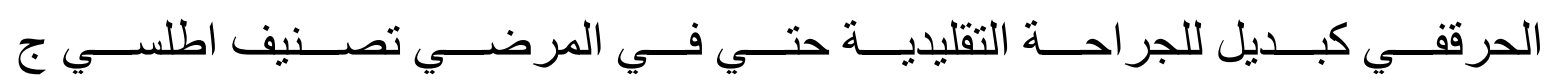

